\title{
SOLUSI SOLITON GELAP ONSITE PADA PERSAMAAN SCHRÖDINGER NONLINIER DISKRIT DENGAN PENAMBAHAN PARAMETRIC DRIVING
}

\author{
MAIDILLA ISWARI, MAHDHIVAN SYAFWAN, MUHAFZAN \\ Program Studi Magister Matematika, \\ Fakultas Matematika dan Ilmu Pengetahuan Alam, Universitas Andalas, \\ Kampus UNAND Limau Manis Padang, Indonesia, \\ maidillaiswari@yahoo.co.id
}

\begin{abstract}
Abstrak. Paper ini mengkaji tentang hampiran solusi soliton gelap onsite dari persamaan Schrödinger Nonlinier Diskrit (SNLD) dengan penambahan parametric driving menggunakan metode analitik Aproksimasi Variasional (AV). Hasil-hasil yang diperoleh secara analitik kemudian dibandingkan dengan hasil-hasil numerik, dimana solusi soliton AV dengan solusi numerik memiliki kesesuaian yang cukup bagus untuk $\varepsilon$ yang semakin kecil.
\end{abstract}

Kata Kunci: Persamaan Schrödinger nonlinier diskrit, soliton, aproksimasi

\section{Pendahuluan}

Persamaan Schrödinger nonlinier diskrit (SNLD) sering ditemukan pada berbagai bidang aplikasi, seperti dinamika sistem osilator tak harmonik terikat (coupled), perambatan serat optik pada pandu gelombang nonlinier terikat, dan dinamika kondensasi Bose-Einstein (Bose-Einstein Condensation) yang terperangkap dalam potensial periodik [12].

Hal yang menarik dari persamaan SNLD ini adalah eksistensi solusi soliton yang dimilikinya, yaitu gelombang yang dapat mempertahankan bentuknya ketika merambat dengan kecepatan konstan meskipun setelah berinteraksi dengan soliton lain $[4,8]$.

Dalam perkembangannya, persamaan SNLD dikembangkan dengan menambahkan parametric driving pada persamaan tersebut. Pengaruh penambahan parametric driving pada persamaan SNLD terhadap kestabilan solusi solitonnya telah dikaji oleh Syafwan dkk [10].

Persamaan SNLD merupakan salah satu persamaan yang tidak dapat ditentukan solusi eksaknya, sehingga salah satu cara yang dapat dilakukan untuk menyelesaikan persamaan tersebut adalah dengan mengembangkan metode analitik untuk menghampiri solusinya. Salah satu metode yang cukup dikenal dan sering digunakan adalah metode aproksimasi variasional. Untuk selanjutnya, metode aproksimasi variasional disingkat menjadi metode $\mathrm{AV}$.

Pada model persamaan SNLD dengan kenonlinieran bertipe kubik, metode AV telah digunakan oleh Aceves dkk [1] untuk mengaproksimasi solusi soliton onsite, yaitu site yang tereksitasi tunggal (one-excited site). Kemudian Cuevas dkk [3] juga 
menggunakan metode AV untuk menghampiri solusi soliton intersite, yaitu site yang tereksitasi ganda (two-excited site) dengan konfigurasi simetris. Selanjutnya, Kaup [6] menyempurnakan metode AV sehingga berhasil menghampiri solusi soliton intersite asimetris.

Metode AV telah digunakan oleh Syafwan [9] dalam menentukan hampiran solusi soliton cerah (bright soliton) bertipe onsite pada persamaan SNLD dengan penambahan parametric driving untuk kasus limit anti-continuum. Hasil yang diperoleh dari metode AV sangat akurat dengan hasil-hasil numerik dalam menentukan hampiran solusi soliton. Kemudian Alfiany [2] telah mengkaji solusi soliton cerah bertipe intersite dan hasil yang diperoleh dengan metode AV sangat baik dalam menghampiri solusi soliton yang diperoleh secara numerik untuk konstanta pengikat yang semakin kecil dan nilai parametric driving yang semakin besar. Dalam paper ini, kajian pada [9] dan [2] akan dikembangkan untuk menentukan hampiran solusi soliton gelap (defocusing) bertipe onsite menggunakan metode AV.

Paper ini disusun dengan sistematika sebagai berikut. Pada bagian kedua berisi tentang analisis awal dari persamaan SNLD. Bagian ketiga berisi tentang formulasi aproksimasi variasional. Perbandingan hasil aproksimasi variasional dengan hasil numerik dibahas pada bagian keempat. Terakhir, pada bagian kelima dikemukakan kesimpulan dan saran-saran untuk penelitian selanjutnya.

\section{Analisis Awal}

Persamaan SNLD stasioner bertipe defocusing dengan penambahan parametric driving diberikan oleh

$$
-\varepsilon\left(u_{n+1}-2 u_{n}+u_{n-1}\right)-\Omega u_{n}-\gamma \bar{u}_{n}+\left|u_{n}\right|^{2} u_{n}=0 .
$$

Pada paper ini secara khusus akan ditentukan solusi soliton gelap onsite dari Persamaan (2.1) dengan syarat batas

$$
u_{n} \rightarrow \pm a \text { bilamana } n \rightarrow \pm \infty \text { dan } a \neq 0 .
$$

Pada kasus $\gamma=0$, persamaan (2.1) memiliki invarian gauge atau invarian fasa, yaitu jika dikenakan suatu transformasi $u_{n} \rightarrow u_{n} e^{i \theta}$ untuk setiap nilai $\theta \in \mathbb{R}$ maka Persamaan (2.1) tidak berubah. Pada kasus $\gamma \neq 0$, persamaan (2.1) tidak lagi memiliki invarian gauge karena terdapat suku kompleks konjugat. Namun jika dikenakan transformasi $u_{n} \rightarrow u_{n} e^{i \theta}$ untuk nilai $\theta=\pi+2 k \pi$ dan $\theta=-\frac{\pi}{2}+2 k \pi$ dengan $k \in \mathbb{Z}$, Persamaan (2.1) secara berturut-turut memiliki simetri refleksi dengan transformasi

$$
u_{n} \rightarrow-u_{n}
$$

dan

$$
u_{n} \rightarrow-i u_{n}, \quad \gamma \rightarrow-\gamma
$$

Dari transformasi (2.4) dapat disimpulkan bahwa nilai $\gamma$ pada Persamaan (2.1) dapat dipilih untuk nilai $\gamma>0$.

Selanjutnya, sebagaimana yang sudah disebutkan sebelumnya, jika $\gamma=0$ maka solusi soliton pada Persamaan (2.1) yang memenuhi kondisi (2.2) bernilai riil $[5,7]$. Sedangkan pada saat $\gamma>0$ terdapat dua kemungkinan solusi, yaitu solusi bernilai 
riil saja (dengan syarat $\Omega+\gamma>0$ ) atau imajiner murni (dengan syarat $\Omega-\gamma>0$ ), dimana solusi bernilai imajiner murni selalu tidak stabil [11]. Oleh karena itu, dalam paper ini akan ditentukan solusi dari Persamaan (2.1) yang bernilai riil, sehingga Persamaan (2.1) dapat disederhanakan menjadi

$$
-\varepsilon\left(u_{n+1}-2 u_{n}+u_{n-1}\right)-(\gamma+\Omega) u_{n}+u_{n}^{3}=0 .
$$

Perhatikan bahwa $(\Omega+\gamma)$ pada Persamaan (2.5) dapat dinormalkan menjadi 1 dengan menggunakan transformasi

$$
u_{n} \rightarrow u_{n} \sqrt{\Omega+\gamma}, \varepsilon \rightarrow \varepsilon(\Omega+\gamma) .
$$

Dengan demikian, tanpa mengurangi keumuman, nilai $\Omega+\gamma$ dapat diganti dengan 1, sehingga Persamaan (2.5) menjadi

$$
-\varepsilon\left(u_{n+1}-2 u_{n}+u_{n-1}\right)-u_{n}+u_{n}^{3}=0 .
$$

\section{Aproksimasi Variasional}

Pada bagian ini akan dijelaskan formulasi aproksimasi variasional (AV) untuk solusi soliton stasioner pada persamaan (2.7). Berikut akan dijelaskan tentang Lagrangian dan fungsi ansatz untuk masalah ini. Lema berikut memberikan Lagrangian dari Persamaan (2.7).

Lema 1. Lagrangian dari Persamaan (2.7) diberikan oleh

$$
L=\sum_{n=-\infty}^{\infty}-2 \varepsilon\left(u_{n} u_{n+1}-u_{n}^{2}\right)+\frac{1}{2}\left(u_{n}^{2}-1\right)^{2} .
$$

Pada saat limit antikontinum $\varepsilon=0$, Persamaan (2.7) memiliki solusi eksak $u_{n} \equiv u_{n}^{(0)}=0, \pm 1$. Untuk soliton gelap tipe onsite, struktur konfigurasinya adalah

$$
u_{n}^{(0)}= \begin{cases}-1, & n \leq-1 \\ 0, & n=0 \\ 1, & n \geq 1\end{cases}
$$

Perhatikan bahwa ketika nilai parameter $\varepsilon$ diperbesar, profil soliton onsite berbentuk fungsi tanh. Kemudian perhatikan pula bahwa amplitude dari $\left|u_{n}^{(0)}\right|$ adalah 1 . Oleh karena itu, untuk menentukan hampiran solusi soliton gelap onsite pada kasus konstanta pengikat lemah, dapat dipilih suatu fungsi ansatz [7].

$$
u_{n}=\tanh (\text { an }), \quad n \in \mathbb{Z}
$$

dimana $a$ adalah parameter variasional yang bernilai riil.

Langkah selanjutnya adalah mensubstitusikan ansatz (3.3) ke persamaan Lagrangian (3.1). Perhatikan bahwa penjumlahan (3.1) menjadi

$$
d \operatorname{lag}(n)=-2 \varepsilon\left(\tanh (\text { an }) \tanh (a(n+1))-\tanh (\text { an })^{2}\right)+\frac{1}{2}\left(\tanh (\text { an })^{2}-1\right)^{2}(3.4)
$$

Fungsi (3.4) sulit untuk diselesaikan penjumlahannya dari $n=-\infty$ ke $n=\infty$. Karena jumlah tak hingga ini sulit untuk dicari nilainya, maka langkah yang bisa dilakukan adalah dengan mengaproksimasinya dengan jumlah hingga untuk $N$ yang cukup besar. 


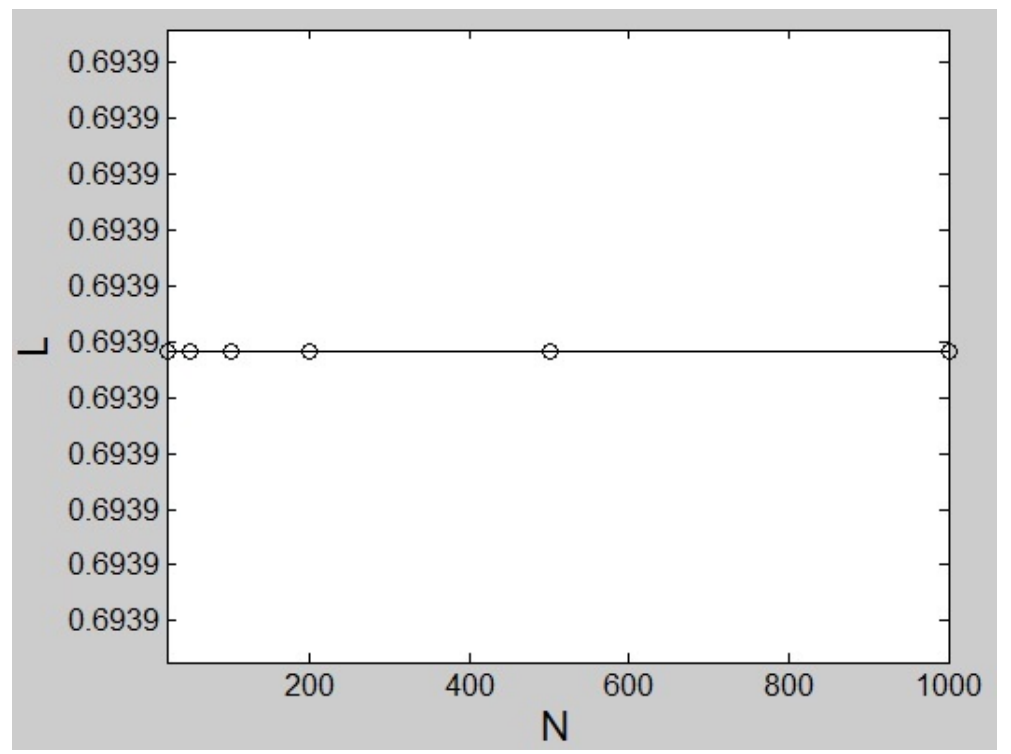

Gambar 1. Plot L terhadap N untuk $a=1$ dan $\varepsilon=0.01$

Pada paper ini, penjumlahan (3.1) akan dihitung untuk $N=10$ dan $N=20$. Hasil yang diperoleh dari kedua $N$ ini tidak terlalu signifikan perbedaannya jika dibandingkan dengan $N$ yang lebih besar. Hal ini dapat dilihat pada Gambar 1 untuk $a=1$ dan $\varepsilon=0.01$.

Dengan menggunakan software Maple, diperoleh hasil penjumlahan (3.1) untuk $N=10$ dan $N=20$ (hasil ini kemudian disebut dengan Lagrangian efektif). Berdasarkan prinsip variasional, Lagrangian efektif $L_{e f f}$ mencapai nilai kritis pada persamaan Euler-Lagrange ketika

$$
\frac{d L_{e f f}}{d a}=0
$$

Hasil yang diperoleh adalah berupa persamaan $f(\varepsilon ; a)=0$ untuk $N=10$ dan $N=20$ (persamaan untuk $N=10$ terlampir). Dikarenakan kompleksitas perhitungannya, nilai parameter variasional $a$ untuk suatu nilai $\varepsilon$ dan $\gamma$ yang diberikan, diselesaikan secara numerik dengan menggunakan software Matlab.

\section{Perbandingan Hasil Aproksimasi Variasional dengan Hasil Numerik}

Hasil-hasil yang diperoleh dengan metode AV akan dibandingkan dengan solusi yang dihitung secara numerik. Solusi numerik untuk soliton gelap onsite pada persamaan (2.7) dapat ditentukan dengan menggunakan metode Newton-Raphson. Perhitungan numerik ini dilakukan pada domain $n \in[-N, N]$ dengan syarat batas $u_{ \pm(N+1)}=u_{ \pm N}$. Sebagai tebakan awal, digunakan solusi soliton eksak ketika $\varepsilon=0$, yaitu diberikan oleh persamaan (3.2). Solusi ini kemudian dilanjutkan secara numerik untuk $\varepsilon \neq 0$. 


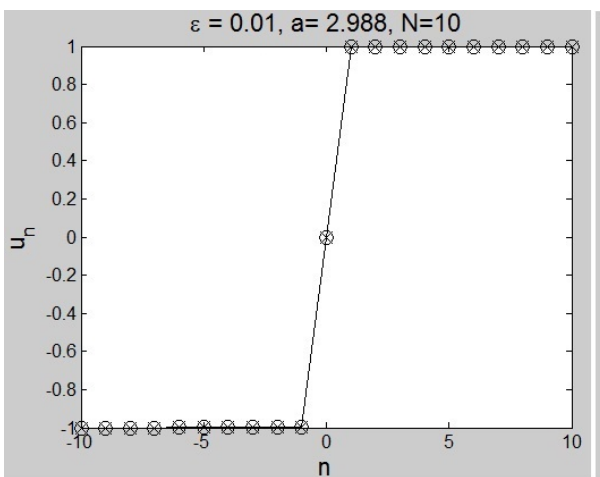

(i)

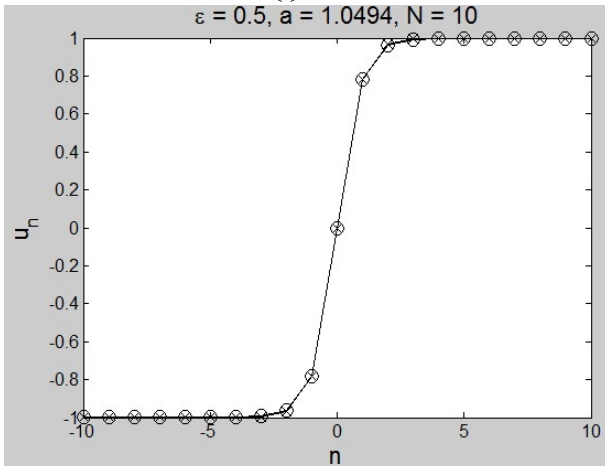

(iii)

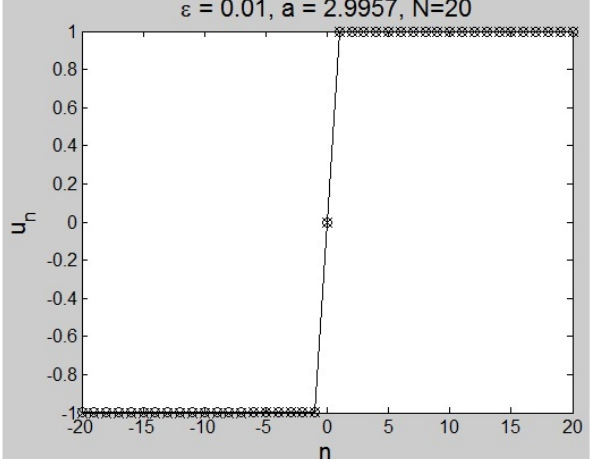

(ii)

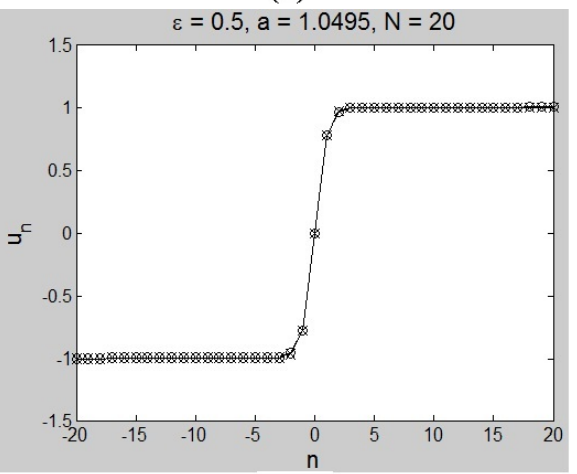

(iv)

Gambar 2. Perbandingan solusi soliton gelap onsite yang diperoleh secara numerik (garisbulat) dengan aproksimasi variasional (garis-silang) untuk $\varepsilon=0.01 ; 0.5$ dan $N=10 ; 20$.

Pertama, pada Gambar (2) diperlihatkan perbandingan antara dua solusi yang diperoleh dari perhitungan numerik dan aproksimasi variasional untuk dua nilai konstanta pengikat $\varepsilon=0,01 ; 0,5$ dan $N=10 ; 20$. Secara umum dapat dilihat bahwa hampiran solusi soliton AV dengan solusi numerik memiliki kesesuaian yang cukup bagus untuk nilai $\varepsilon$ yang lebih kecil.

Kedua, untuk memeriksa lebih lanjut kesesuaian antara hampiran solusi soliton AV dan solusi numerik, diplot norm $l^{2}$ dari kedua solusi sebagai fungsi terhadap $\varepsilon$ untuk $N=10$ dan $N=20$ (lihat Gambar 3).

Berdasarkan Gambar 3 dapat dilihat bahwa norm dari hampiran solusi AV dan numerik nilainya bertambah seiring dengan bertambahnya $N$. Hal ini wajar karena nilai $u_{n}$ semakin banyak digunakan untuk $N$ yang semakin besar. Lebih lanjut, dari nilai eror pada gambar, yang didefinisikan sebagai norm dari selisih solusi soliton secara numerik dan AV, dapat disimpulkan bahwa solusi soliton AV cukup baik dalam menghampiri solusi soliton secara numerik untuk $\varepsilon$ yang semakin kecil.

Ketiga, untuk mengkofirmasi lebih lanjut kesesuaian antara solusi numerik dan solusi AV, berikut akan dibandingkan nilai paramater a yang diperoleh dari AV 

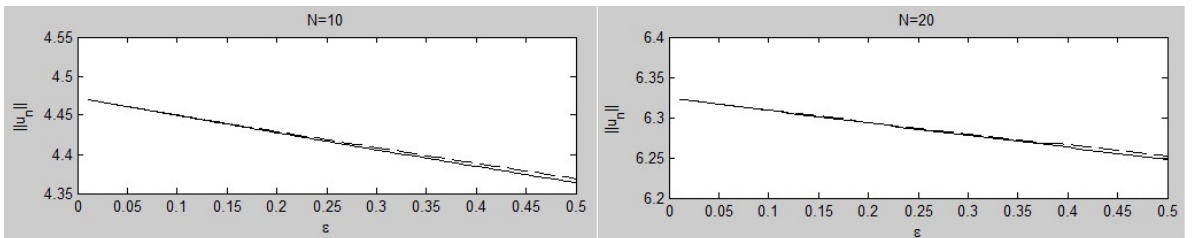

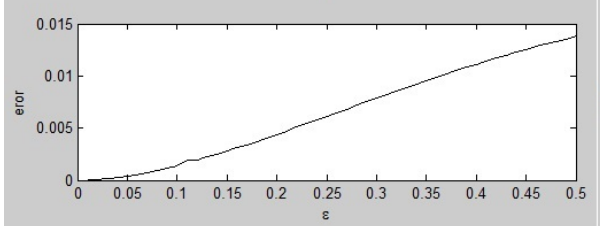

(i)

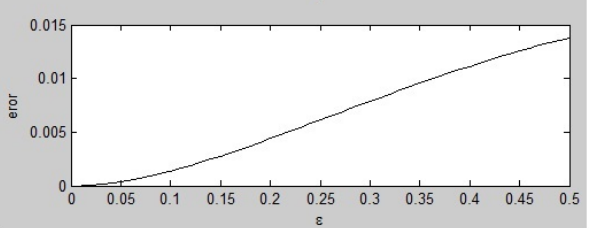

(ii)

Gambar 3. Perbandingan antara nilai norm $l^{2}$ dari solusi numerik (garis utuh) dan solusi AV (garis putus-putus) sebagai fungsi terhadap $\varepsilon$ untuk $N=10$ dan $N=20$.

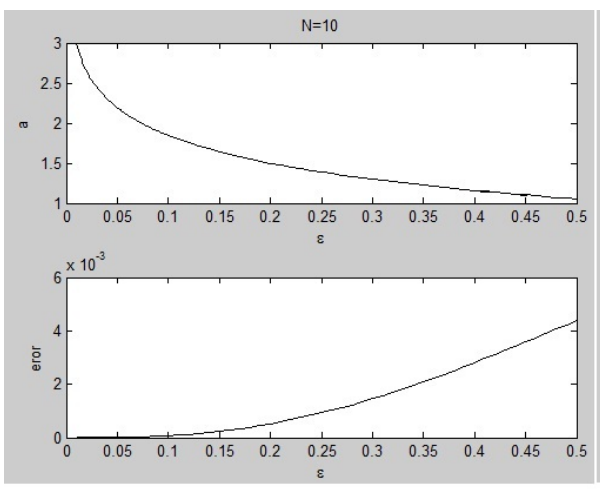

(i)
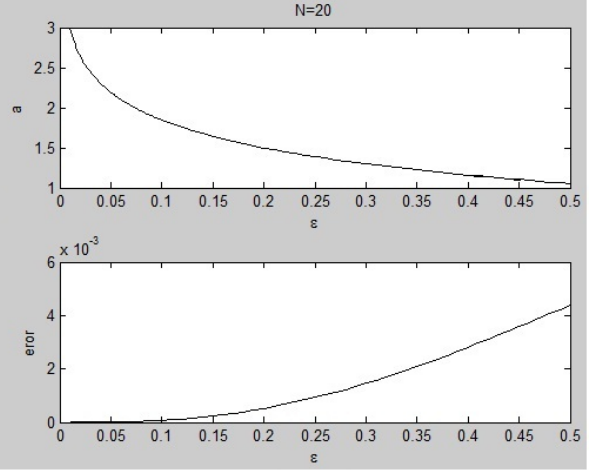

(ii)

Gambar 4. Perbandingan nilai parameter variasional a yang diperoleh secara numerik (garis utuh) dan AV (garis putus-putus).

dengan numerik. Untuk perhitungan nilai $a$ secara numerik, dapat dihitung dengan

$$
a=\frac{\tanh ^{-1}\left(u_{n}\right)}{n}
$$

dimana $u_{n}$ adalah solusi numerik.

Hasil perbandingan nilai $a$ ini diberikan oleh Gambar 4. Dari Gambar 4 dapat disimpulkan bahwa nilai parameter variasional $a$ yang diperoleh secara analitik cukup baik dalam menghampiri nilai parameter variasional $a$ secara numerik.

\section{Kesimpulan}

Pada tulisan ini telah diperoleh bahwa pertama, dengan menggunakan fungsi ansatz $u_{n}=\tanh (a n)$, hampiran solusi soliton gelap onsite dapat ditentukan, meskipun 
dalam perhitungannya Lagrangian efektif diperoleh dari penjumlahan hingga. Kedua, solusi soliton AV dengan solusi numerik memiliki kesesuaian yang cukup bagus untuk $\varepsilon$ yang semakin kecil. Terakhir, Solusi soliton stasioner dan bernilai riil dari persamaan SNLD dengan penambahan parametric driving dapat disederhanakan dengan membuat jumlah parametric driving dan frekuensinya sama dengan satu.

Kepada peneliti selanjutnya agar dapat menghitung limit jumlah tak hingga Lagrangian dan mengkaji kestabilan soliton gelap (onsite maupun intersite) dengan menggunakan metode aproksimasi variasional.

\section{Ucapan Terima kasih}

Penulis mengucapkan terima kasih kepada Bapak Dr. Admi Nazra, Ibu Dr. Lyra Yulianti dan Ibu Dr. Yanita yang telah memberikan masukan dan saran sehingga paper ini dapat diselesaikan dengan baik.

\section{Daftar Pustaka}

[1] Aceves, B., De Angelis, C., Peschel, T., Muschall, R., Lederer, F., Trillo, S., dan Wabnitz, S., (1996), Discrete self-trapping, solitons interactions, and beam steering in nonlinear waveguide arrays, Phys. Rev. E 53, 1172.

[2] Alfiany, N., (2013), Aproksimasi Variasional untuk Soliton Cerah Intersite pada Persamaan Schrödinger Diskrit Nonlinier dengan Penambahan Parameter Driving, Tesis, Universitas Andalas.

[3] Cuevas, J., James, G., Kevrekidis, P. G., Malomed, B. A., dan Sánchez-Rey, B., (2008), Approximation of Solitons in the Discrete NLS Equation, J. Nonlinear Math, Phys. 15124.

[4] Drazin, P. G., dan Johnson, R. S., (1989), Solitons: An Introduction, Cambridge University Press, Cambridge.

[5] Hennig, D., dan Tsironis, G., (1999), Waves Transmission in Nonlinear Lattices, Phys. Rep. 307, 333.

[6] Kaup, D. J., (2005), Variational Solutions for the discrete nonlinear Schrödinger equation, Math. Comput. Simulat. 69, 322.

[7] Kivshar, Y. S. dan Krlikowski, W., (1995), Lagrangian approach for dark solitons, Opt. Comm. 114, 353-362.

[8] Scott, A., (2005), Encyclopedia of Nonlinear Science, Routledge, New york and London.

[9] Syafwan, M., (2012), Variational Approximations for Solitons in a Parametrically Driven Discrete Nonlinear Schrödinger Equation, Prosiding Seminar Nasional Matematika, Universitas Andalas, ISBN 978-602-95343-2-0, 52-58.

[10] Syafwan, M., Susanto, H., dan Cox, S. M., (2010), Discrete Solitons in Elektromechanical Resonator, Phys. Rev. E 81, 026207.

[11] Syafwan, M., (2012), The Existence and Stability of Solitons in Discrete Nonlinear Schrödinger Equations, Disertasi Doktor, University of Nottingham.

[12] Trombettoni, A. dan Smerzi, A.,(2001), Discrete Solitons and Breathers with Dolute Bose Einstein Condensates, Phys. Rev. Lett. 86, 2353. 